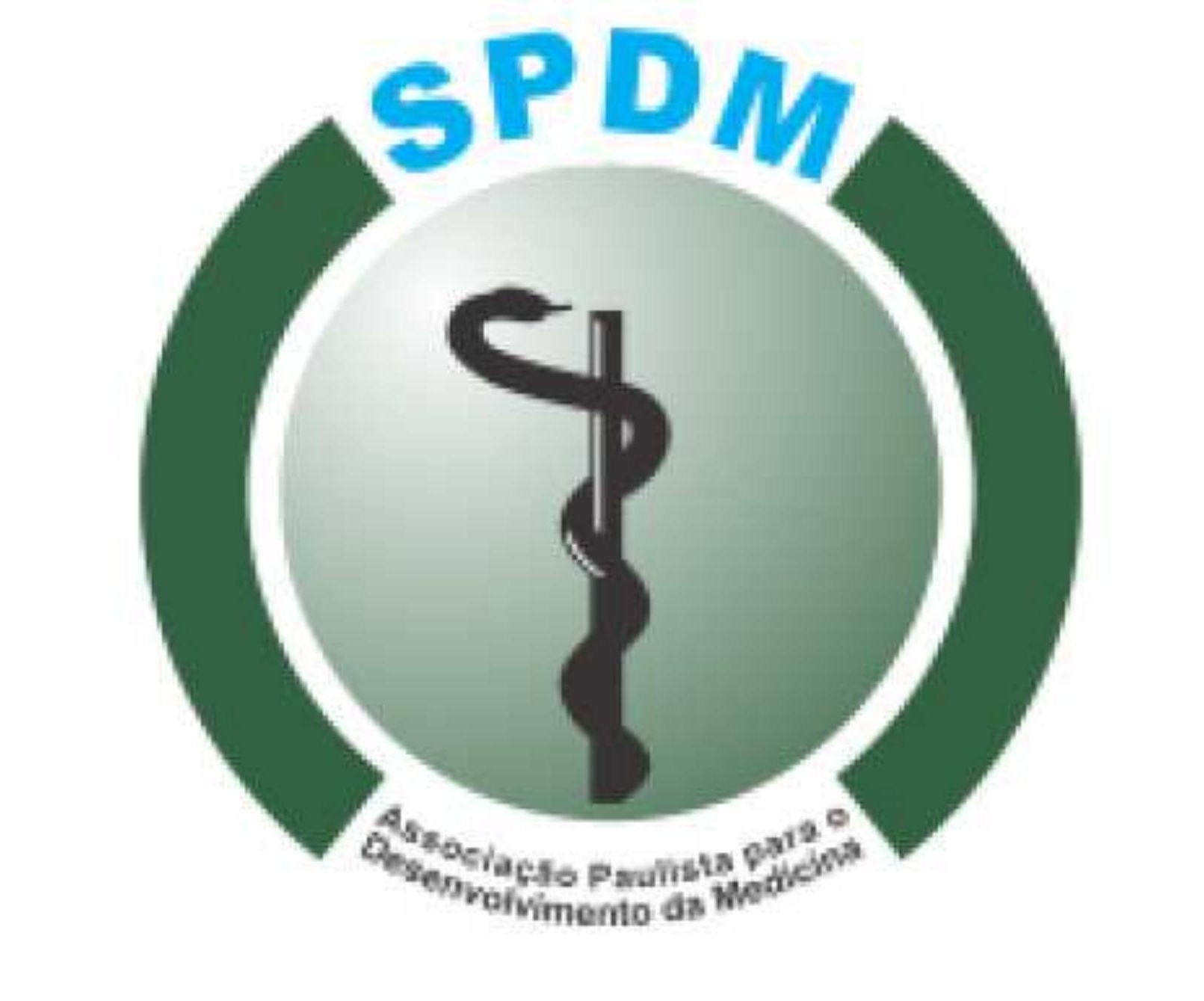

\title{
REDUÇÃO DE INFECÇÃO DE CORRENTE SANGUÍNEA RELACIONADA A CATETER VENOSO CENTRAL EM UM HOSPITAL MUNICIPAL DE SÃO PAULO
}

\author{
Eixo temático: Avaliação e qualidade do cuidado
}

\author{
Andrea Mayumi Loureiro Hayashi; Edimara Dias; Marcia Cristina Marques do Nascimento, Solange Felomeno \\ Caramello Hypolito, Vanessa Cerávolo Gurgel Silva
}

\section{INTRODUÇÃO}

A Agencia Nacional de Vigilância Sanitária (ANVISA) destaca que infecções da corrente sanguínea são multifatoriais e apresentam fisiopatologia, critérios diagnósticos, implicações terapêuticas, prognósticas e preventivas distintas. ${ }^{1}$ As infecções primárias de corrente sanguínea em grande parte estão associadas a algum dispositivo intravascular. ${ }^{2}$ O processo de avaliação e intervenções educacionais são importantes para verificação de conformidades das práticas assistenciais esperadas e são instrumentos fundamentais que permitem tanto diagnósticos iniciais, como ações direcionadas. $^{3}$

\section{OBJETIVO}

Descrever a diminuição do número de infecção de corrente sanguínea relacionado a CVC no Hospital Município Vereador José Storopolli em São Paulo.

\section{METODOLOGIA}

Este estudo foi realizado através da inserção do projeto do $\mathrm{IHI}$ que visa melhorar a Segurança do paciente em Larga Escala no Brasil na UTI do Hospital Municipal Vereador José Storopolli em 2018, utilizando algumas iniciativas que foram colocadas em prática bem como intervenções pontuais, regulamentadas por protocolos difundidas através de educação continuada e avaliadas diariamente pelos profissionais integrados no processo

\section{RESULTADOS}

Foi observado a melhora significativa de adesão aos protocolos instituídos e tendo como conseqüência a redução ao marco zero do número de infecções por um período de 240 dias em 2018. Percebeu-se também que a equipe se tornou mais engajada ao processo do cuidar, quando apresentados aos resultados positivos das suas ações.

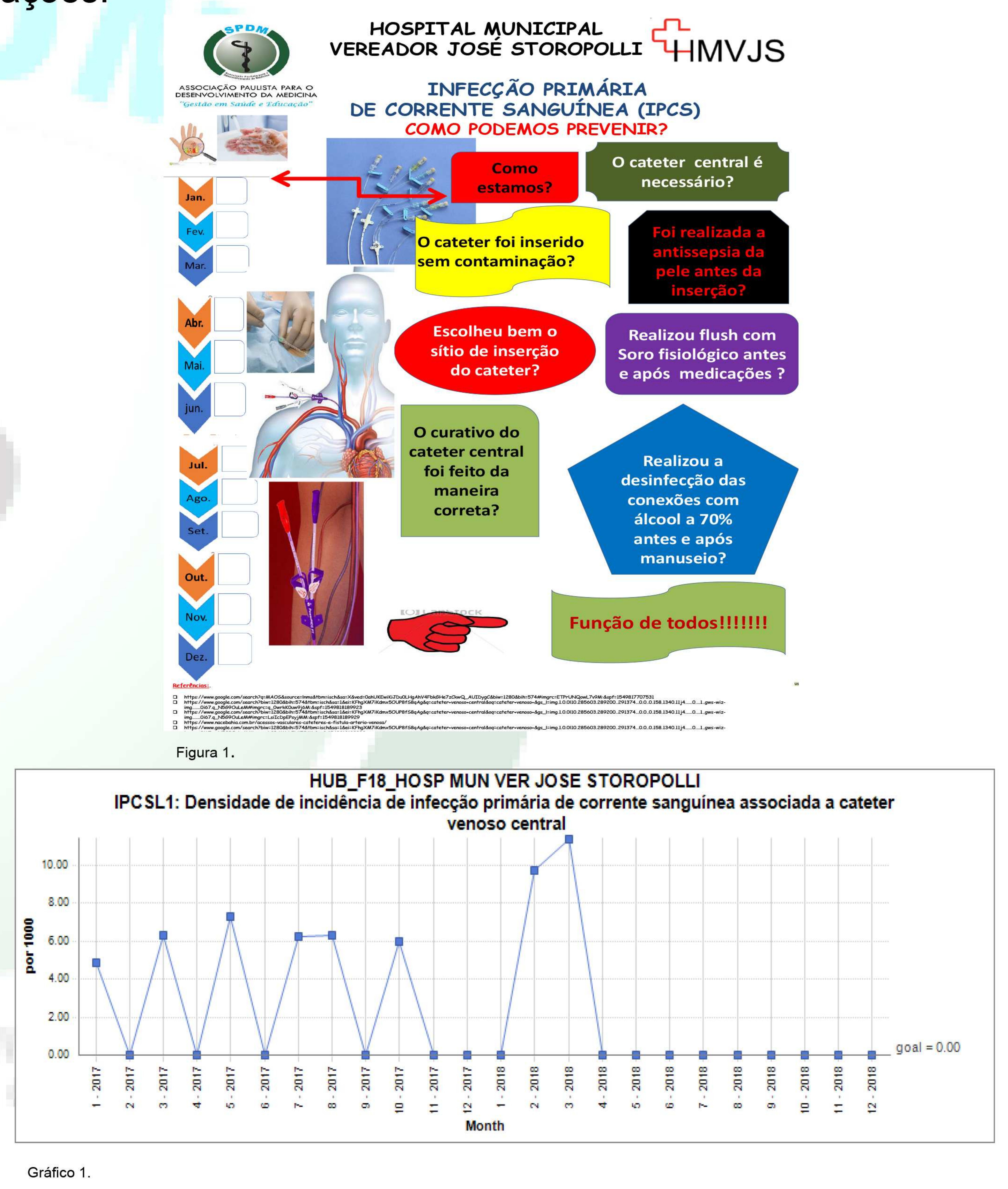

\section{CONCLUSÃO}

Os resultados deste estudo permitiram avaliar que houve adesão maciça da equipe de enfermagem, tendo em vista que, somente através da participação de todos os profissionais envolvidos na redução de infecção de CVC, demonstrado através do gráfico acima, foi possível obter resultados de excelência e com o mínimo de recursos necessários.

\section{REFERÊNCIA}

1 - Brasil. Agência Nacional de Vigilância Sanitária. Corrente Sanguínea, Critérios Nacionais de Infecções Relacionadas à Assistência à Saúde. Setembro, 2009

2 - Brasil. Agência Nacional de Vigilância Sanitária. Infecção de Corrente Sanguínea. Orientações para Prevenção das Infecção Primária de Corrente Sanguínea. Agosto, 2010

3 - Jardim JM, Lacerda RA, Soares NJD, Nunes BK. Avaliação das práticas de prevenção e controle de infecção da corrente sanguínea em um hospital governamental. Rev Esc Enferm USP; maio 2013, 47(1):38-45 